\title{
A Study on Learning Behavior of Fine Arts Majors
}

\author{
Yaqiong Li \\ Eastern International Art College \\ Zhengzhou University of Light Industry \\ Zhengzhou, China
}

\begin{abstract}
It is the key link and precondition for education and teaching reform to understand and grasp the students' learning behavior characteristics. The study and optimization strategy of learning behavior of students majored fine arts will promote the college teachers of fine arts to better grasp the educational object's learning orientation, and gradually enhance the prediction and guidance of learning behavior of students majored in fine arts, adding the educating effectiveness.
\end{abstract}

Keywords-students majored in fine arts; learning behavior; characteristic optimization strategy

\section{INTRODUCTION}

There are numerous learning behavior of students majored in fine arts that can be observed by us in learning and practice. From the point of learning place, it can be divided into classroom learning behavior and non-classroom learning behavior. Of which, classroom learning behavior occupies the core position constantly. From the point of learning medium, it can be divided into the learning behavior with network as the medium and the learning behavior with books as the medium. Among them, the network media is becoming the most important emerging media for arts learning with its timeliness and frontier, having sufficient expansion space. From the perspective of the forms of learning outcomes, creative learning behavior is the advanced form of the numerous learning behaviors of students majored in fine arts, and the study on creative learning behavior should also be the important topic in the field of higher education of fine arts. So, the above three kinds of typical learning behaviors are the main explicit carrier of learning behavior of students majored in fine arts, which will be described in detail below.

\section{SURVEY AND ANALYSIS OF LEARNING BEHAVIOR OF STUDENTS OF FINE ARTS}

\section{A. Classroom Learning Behavior of Students of Fine Arts}

Classroom teaching is an activity specially organized to teach knowledge in the class situation, and the process to make students grasp systematic scientific knowledge and skill gradually through teachers' guidance and students' active learning, and develop students' cognitive ability on the basis of that.

In the survey of judgment on different courses' effectiveness by students of fine arts, students will different majors offered almost the same answer. $87.2 \%$ of the students believe the course which may be skipped will be Political Theory "Fig. 1". The pressure and challenge faced by the theory course teacher of fine arts colleges, especially the "twocourse" teachers, are obvious. Its reasons may be the following three aspects. First of all, the students of fine arts are more lively and free with distinctive personality and indifferent of the authority compared with the general students of liberal arts and science. Second, the society and market tend to evaluate and choose them by virtue of the professional skills of students of fine arts, which make those students put most of their energy on professional learning and skill creation, and ignore public theory course. Third, part of the teachers cannot clearly recognize the characteristics of students of fine arts, and they have ideological bias toward the students, thinking them have weak general knowledge with little thirst of knowledge, being the most disobedient students. These teachers neglect management in class and their teaching methods are outdated. Some $10.3 \%$ of the students ignored the role and position of art theory class, just lay emphasis on technical ability and actual operation level. 


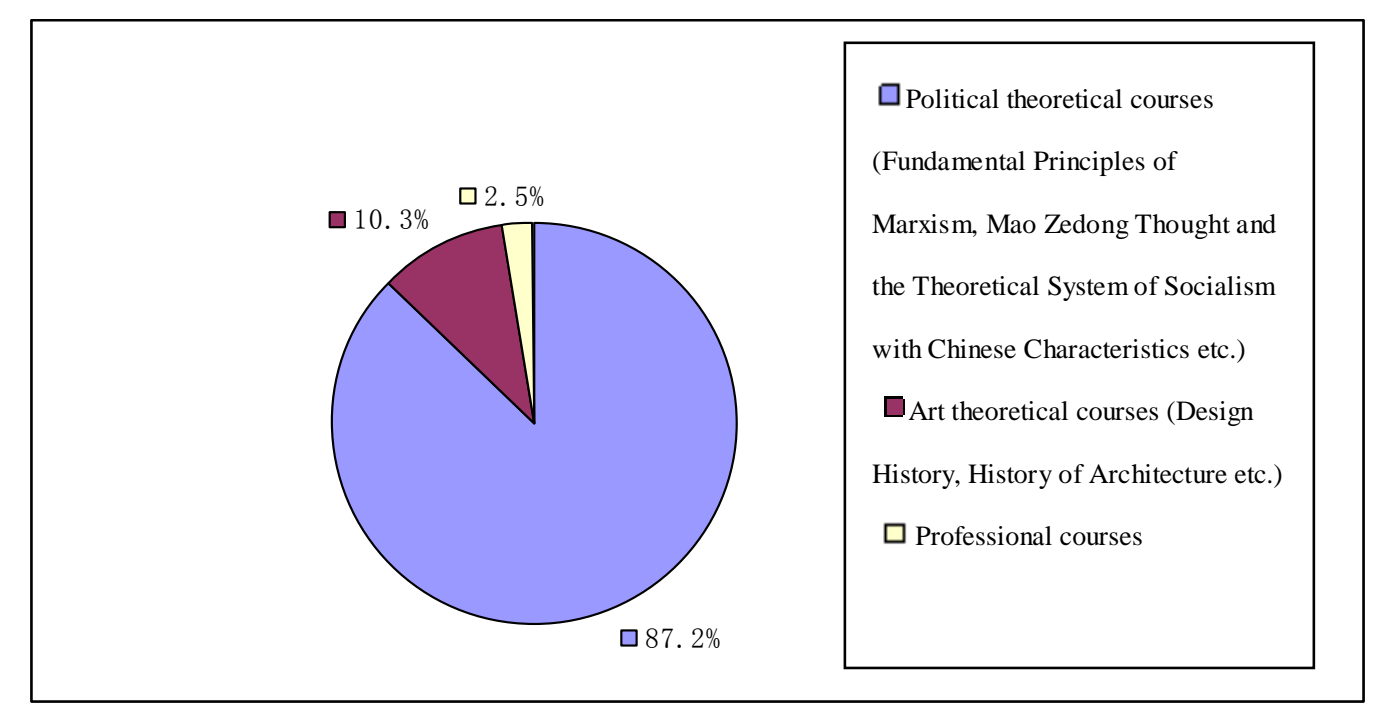

Fig. 1. Courses those are easy to be skipped by students of fine arts

As for the survey on the accomplishments teachers need to have "Fig. 2", about $45.5 \%$ of the students value the teachers' professional level and teaching art, thinking that the profound knowledge system and professional skills, vivid classroom organization and attraction is the key standard to evaluate an excellent teacher. And $25 \%$ of the students think that an excellent teacher shall have noble moral character and practical and patient teaching attitude.

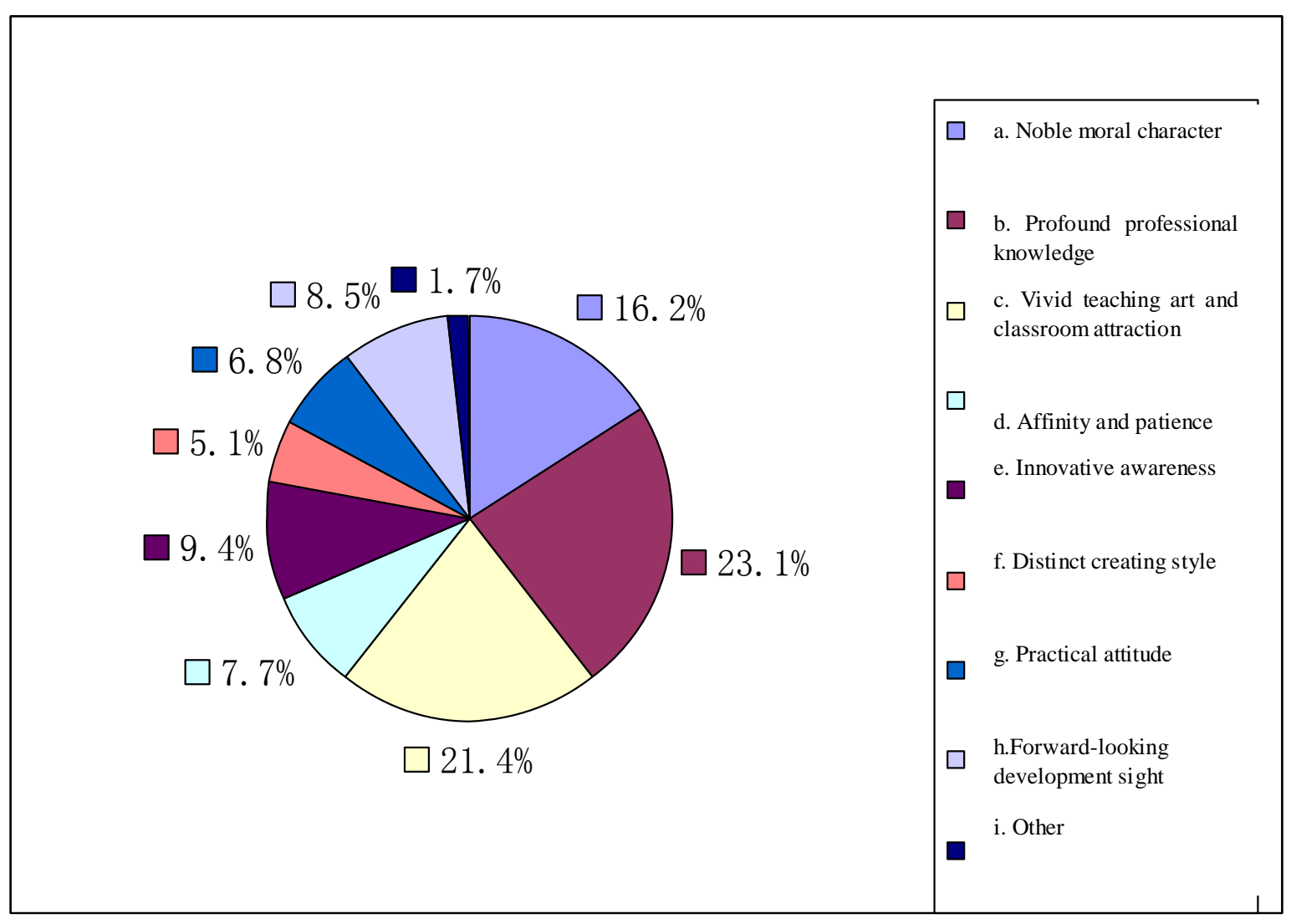

Fig. 2. Accomplishments that the students of fine arts think the teachers shall have

In the survey on classroom misbehaviors, $89.5 \%$ of students said they don't agree with or says he won't be absent from school. This shows that the students of fine arts has initially formed the rigorous discipline consciousness and 
learning values, not the students who are naughty and weary of studying generally believed by the society. When asked the reasons why students of fine arts will absent from a class, about $43.75 \%$ of the students said may be they use the time to do some more meaningful things. About $23.55 \%$ of the students think this course is not important. About $22 \%$ of the students think the reason is the teacher's teaching is boring. $10.7 \%$ of the students think that because they are lazy and want to take the time to sleep. So, in view of the students of fine arts, we cannot blindly think that they do not love learning and let them do what they like, or blindly believe that they are difficult to control, and use the method of "big stick" to call them go to class. To improve the classroom attraction, it is necessary to let students experience the benefits and practicability of classroom teaching from his heart, and strengthen the teachers' level of classroom teaching art to improve the attraction of classroom teaching.

In the survey on classroom initiative of students of fine arts, the researchers found that they are generally in a passive state. More than half of the students said they won't participate in classroom interaction activities; especially the performance of students of higher grades in class is more closed. Because of the needs of cooperative design, the graduating students' enthusiasm has improved. "Fig. 3" This shows that, on the one hand, the students of fine arts lack the habit of active thinking and consult; on the other hand, it also shows that the teachers haven't guided students to aware their passive learning behavior and taken initiative to improve.

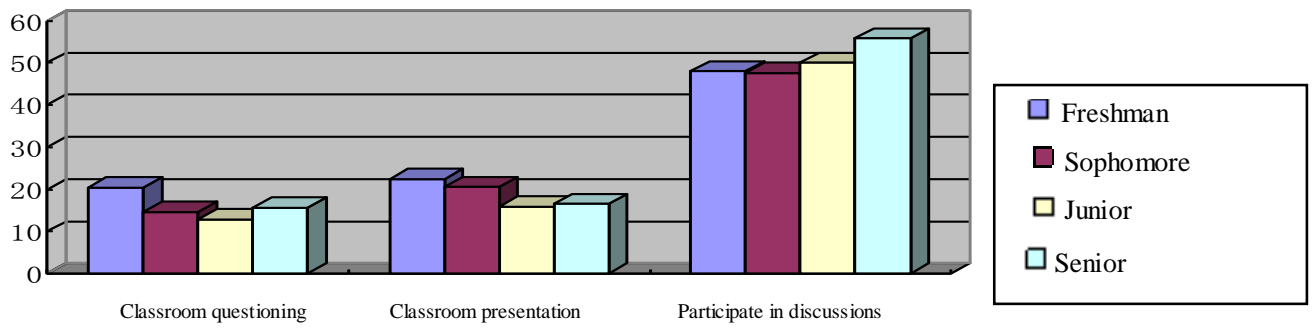

Fig. 3. Differences in classroom behaviors of different grades

In order to reveal the differences between students of fine arts and the domestic and foreign general students in terms of classroom performance, this paper has made a comparison between students of fine arts and part of students from universities of "985 Project" and the students of American research universities [1] "Fig. 4". The comparison shows that students of fine arts have no obvious disadvantage in discussion and cooperation, but lack the habit of active thinking and consult, on the other hand, it also shows that teachers haven't not guided students to aware their passive learning behavior and taken initiative to improve.

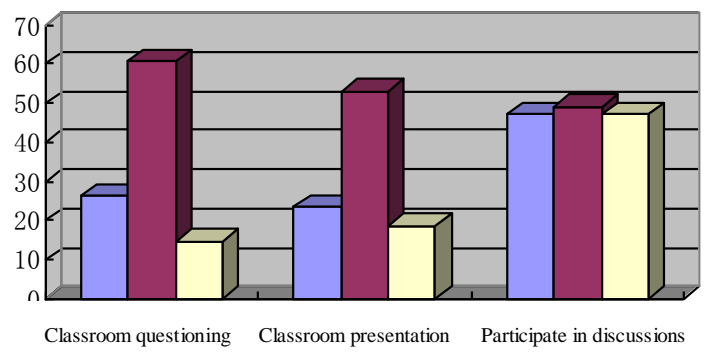

$\square$ Part of the universities of "985 Project"

$\square$ American top research university

$\square$ Part of the universities of fine arts

Fig. 4. Differences between students of fine arts and general students from domestic and foreign universities in terms of classroom performance

\section{B. E-learning Behavior of students of Fine Arts}

E-learning behavior refers to the autonomous learning behavior made by learners using computer and network media. As for the students of fine arts, e-learning has increasingly become an important part of their learning style. In the survey, about $95.85 \%$ of the students think that the network has provided effective help in learning. There are investigation and survey suggesting that students of fine arts (especially the students of fine arts - design) have regarded network resources as the important way to gain daily learning resources, and their demand for network resources is more urgent compared with the ordinary students of liberal arts and sciences [1] "Fig. 5". Therefore, the educators of fine arts of higher education shall pay more attention to the development and utilization of network teaching platform, and take initiative to create the "second classroom", to increase the interaction between teachers and students under the network environment. On the survey Internet's contents to be used, $61.1 \%$ of students said they only use the Internet to collect information, only $14.5 \%$ of the students said using the Internet to communicate and make interactions with the teacher, and $24.4 \%$ of the students said 
they will participate in the self-study activities of learning website and forums. This shows that the use of network by students of fine arts is relatively simple, lack of participation and interaction, and needs to be improved and developed further. This will also put forward a new thinking for the teacher of fine arts colleges and universities (especially the professional teachers): how to deal with and participate in the e-learning activities of students of fine arts.
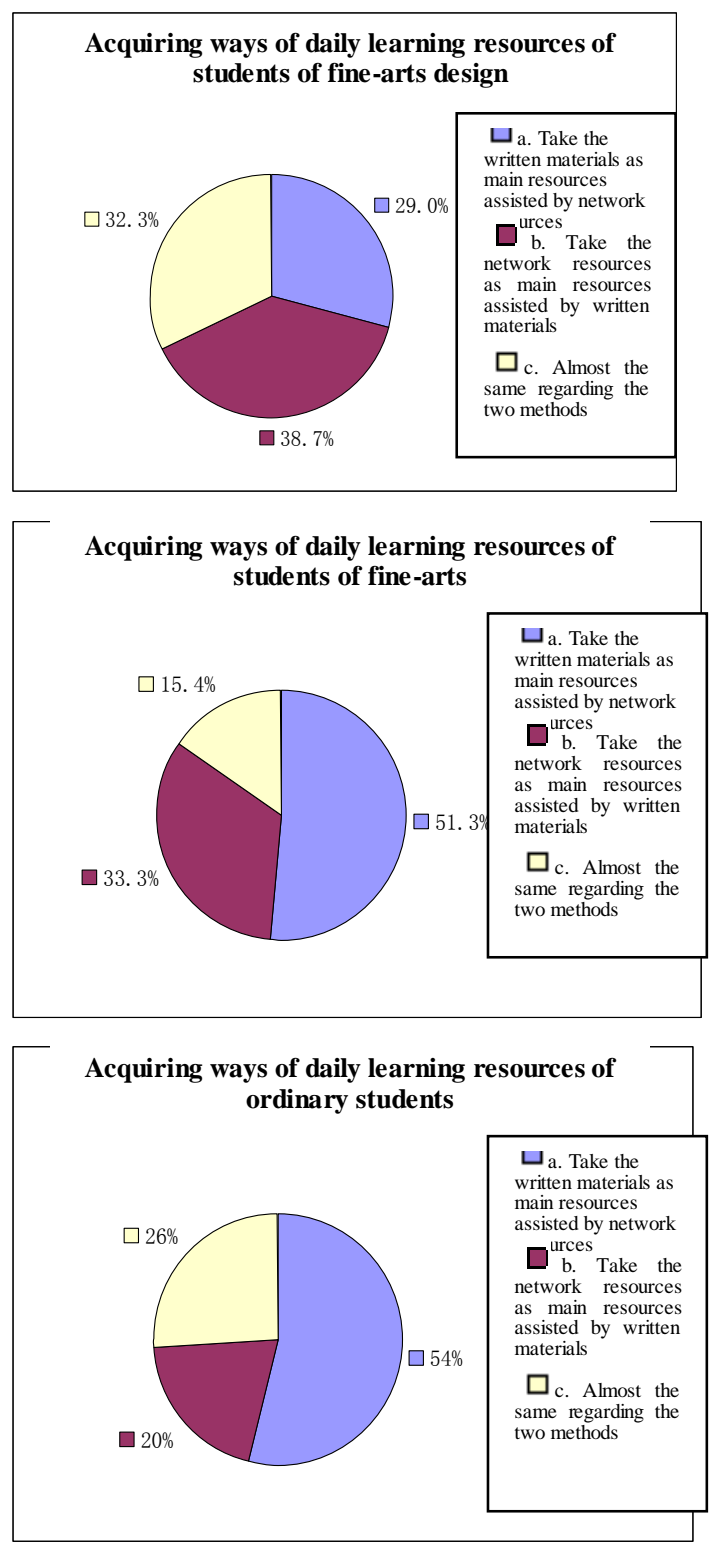

Fig. 5. Differences between students of fine arts and ordinary students in terms of learning resources ways

In the dialectical evaluation on e-learning behavior "Fig. 6", about $38.7 \%$ of the students think the Internet is more suitable for study, design and creation, another $61.3 \%$ of the students put forward their different views: among them, $32.3 \%$ of the students think the information on Internet is numerous and complex which leads to lower learning efficiency; $19.4 \%$ of the students think that online learning is not systematic enough; and $9.6 \%$ of the students think that the form online learning is too free, resulting in difficult to study in-depth.

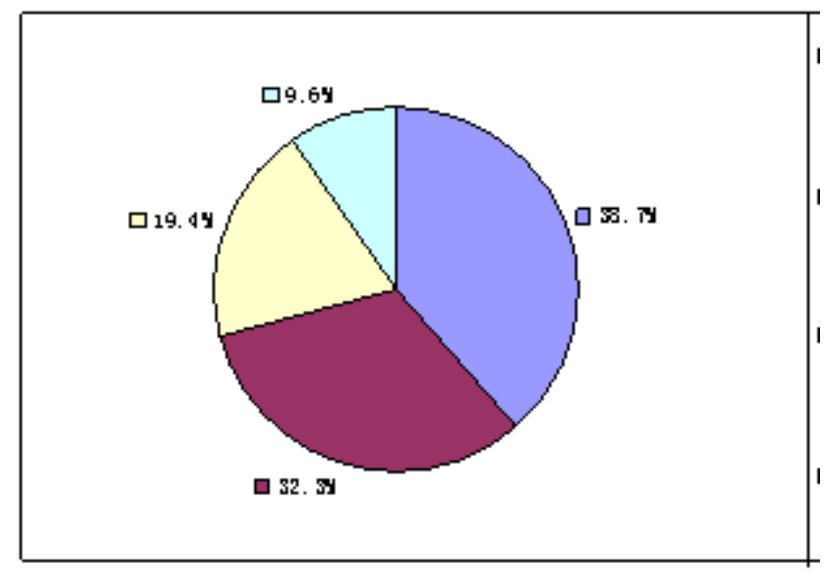

$$
\begin{aligned}
& \square \text { a. Suitable for study, design and creation from form to } \\
& \text { contents } \\
& \square_{\text {b. Strong learning function, but with low learning quality and }} \\
& \text { efficiency } \\
& \square_{\text {c. The contents are not abundant enough although the form is }} \\
& \text { free } \\
& \square \text { d. The form is too free, resulting in difficult to study in-depth }
\end{aligned}
$$

Fig. 6. Evaluation on e-learning behavior by students of fine arts

\section{Creative Learning Behavior of Students of Fine Arts}

If the specialties of fine arts pay no attention to the combination with design ideas and technical course construction, then they will develop into the simple copy and repetition of existing creation style and level. As early as the Bauhaus school of design, art educators began to call for the unity of art and technology. Latter, the United States and Britain and other countries paid more attention to the combination of art education with economic, business, management and other disciplines with the purpose to avoid the mistake of "empty tall" [1]. In fact, the accumulation of design experience and exercise of creative skills can also be improved in teaching, namely extend the simple classroom learning to the creative learning behavior combining classroom learning and social learning.

In the survey on the source of art practice and creation, about $42.45 \%$ of the students think it is from the platform and channel established by school and the art practice courses and activities arranged by the school. $21.49 \%$ of the students think it is form the enlightenment and guidance of teachers. And $20.96 \%$ of the students said it comes from the observation of life and their own creation quality. Data illustrates that in creation practice link, students tend to depend on school and teachers with great expectation, hoping school and teachers can provide a wider range of ways and give more support. How to optimize and create creative learning activities for students of fine arts in the category of school education should be the topic to be thought with emphasis in higher education field of fine arts. 
Based on the creation characteristic of fine arts achievements, students' cooperative learning ability in learning is especially prominent. On some research literatures relating to fine arts, they all conclude that those students are "maverick and lack of cooperation consciousness". But in the survey made the author on "teamwork" in homework completion stage, the results show that about $87.1 \%$ of the students said it is very important to cooperate with others in learning, reflecting the strong consciousness and initiative tendency. Their cooperation consciousness presents to be at quite a high level during their freshman period, and is fully recognized when they are senior students "Fig. 7".After an interview, the author finds that the reason is that students of fine arts has experienced a long term of art training outside school and art exams in the period of their twelfth grade, and a relatively complete independent consciousness, companion consciousness and affinity to groups are cultivated, which has laid foundation for the team awareness in their college period. In the process of completing daily assignments, the creation in groups also provides the external environment for the development of their cooperation consciousness. And in the graduation design phase, they tend to present more dependence and trust on creation companion [1].

Trend of cooperative consciousness by Grads

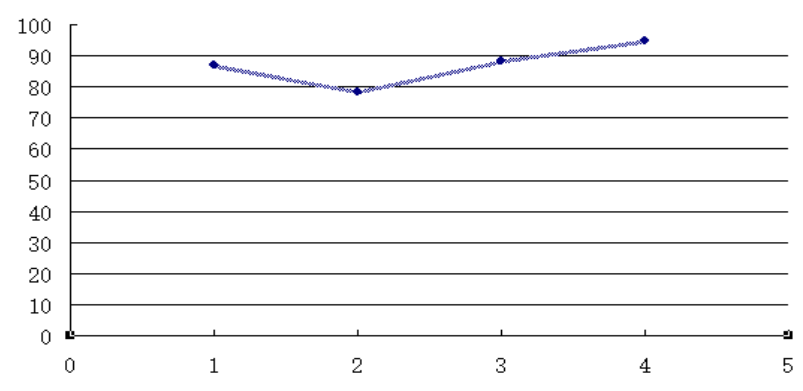

Fig. 7. Trend of the cooperative consciousness of students of fine arts by Grads

Apparently, students of fine arts are not lack of cooperative creation concept, and "maverick" only represents the thinking way of students of fine arts in observing the world and the different creation styles between individuals. Through interviews, the author found that the independent individual thinking style and creative ideas will not result in contradictions in cooperation, on the contrary, it will generate more prefect creative program and practice effect after effective communication and interactive discussion.

\section{OPTIMIZING STRATEGY OF LEARNING BEHAVIOR FOR STUDENTS OF FINE ARTS}

\section{A. Strengthen the Effectiveness of Classroom Learning Behavior for Students of Fine Arts, and Enhance the Course Value}

With the further development of the new curriculum reform, the understanding and definition of effective teaching also get enriched and perfected. This study will analyze the effectiveness of classroom learning behavior of the students of fine arts from the following two dimensions: grasping of knowledge and skills, acquiring of humanistic value. Take the teaching of traditional Chinese painting as an example, practice is the basic way of professional learning of traditional Chinese painting at university level, and the mastering of composition, color and skills is the basis for the creation in this specialty. The presentation of effective knowledge and skills is an important condition to guarantee an effective classroom teaching. In the process of acquiring knowledge and skills, we shall further guide the students to understand the national aesthetic characteristics and performance characteristics, to experience in person the splendid national painting culture and the inner world that has been touched. On the basis of perceptual experience, lead "skill" to "principal", and encourage and mobilize the initiative of students, to promote their cognition of exploring, correction, and improvement of the art form of "Chinese painting", and try to get the right to express their mind through their own paintings. To ensure the creation quality and scientificity of students of fine arts, we must pay more attention to cultural value in the works, require the teachers to constantly break down barriers between disciplines, to penetrate more widely into humanities and social science as well natural science, strengthen the relationship between courses and their integration, make students experience the benefits and practicability of classroom teaching and from heart, and strengthen the teachers' classroom teaching art level, enhance the attraction of classroom teaching.

In classroom teaching, teachers must set up the consciousness of "course value", and commit to designing the classroom structure carefully, arouse students' positive thinking and exploration, improve the course's career orientation, continuously introduce in the advanced information and mainstream consciousness, increase the cohesion of learning activity with and application and real life. Moreover, the students of fine arts generally have strong sensibilities, careful observation, active thinking, wide experience and strong independent cognitive ability with independent position in perception of things, which are more conducive to create the classroom atmosphere of thinking, discussion and analysis. Teachers can set thinking situation through stimulate students' curiosity, to guide them enhance interest, to make active exploration, perceive the pleasure of classroom learning, and realize the course value.

\section{B. Strengthen the Construction of E-Learning System for Students of Fine Arts and Supervision of Students' Network Behavior, and Adjust the Interactions between Teachers and Students under Different Learning Medium}

At present, the network media and computer technology are widely used in the field of education, and the learning behavior with network as the medium is also increasingly become the general learning behavior of students of fine arts, which is directly related to the final learning effect. Their use of network is mainly to get learning resources and computer graphics through search engines, which is basically a simple operating behavior, and lack of analysis, processing and transmission of the information resource, which is still in a relatively low level. Moreover, the network information resources are of varying qualities, generally, students have 
difficulty in distinguishing their quality and efficiency, and are difficult to combine them with the professional study completely. At the same time, the interactive communication made by students of fine arts through network is lack of organization and authority, having the characteristics of spontaneous and uncertainty, etc. This requires the colleges and universities of fine arts to strengthen the construction of campus network and library digital resource database, and develop the network learning system that can adapt to the learning of fine arts course. The teachers must pay attention to the students' network learning behavior, and take initiative to participate in such behavior to play the role of guidance. First of all, the teachers themselves should have good computer operation skills and the network utilization ability, to be able to recommend network learning resources and take the initiative to build a network communication platform between teachers and students, teach students the literature index technique, use the emerging network communication tools, to realize the scientization, systematizing and normalization of the communication between teachers and students as well as between groups. At the same time, the changes in students' learning attitude under network environment shall also be taken into consideration. In the face of complex network environment and the relative free learning form, the students of fine arts tend to be more easily disoriented. Therefore, teachers should strengthen the supervision, management and evaluation of students' network behavior. They can strengthen alert by organizing debate and case study, to make students realize the network media is a "double-edged sword" and take initiative to avoid disadvantages. The teacher also can refine the network learning steps, capture the students' learning outcomes, and conduct inspection and evaluation in a timely manner.

Under the network environment, the role of teachers and students has also changed. Teachers have become the organizers and participants of e-learning activities from the instructors, and students have become the selectors and users of e-learning from the educated ones. Both teachers and students need to change views in a timely manner, to enhance the level of self-discipline and the active consciousness. Moreover, we need to understand that, e-learning is a kind of auxiliary means compared with classroom learning, and the appreciation and understanding of "beauty" need to be brought to the student of fine arts through life experience, visual impact, subjective feelings and hands-on practice.

\section{Pay High Attention to the Creative Learning Behavior of Students of Fine Arts, and Offer Sufficient Methods and Guidance}

Creation is the centralized presentation of the learning quality of students of fine arts, and one of the learning styles throughout the whole learning process during university. How to optimize the creative learning behavior of students of fine arts has become the key to promote the comprehensive learning power. This paper will describe from the following three aspects.

First, optimize the learning behavior facing employment and market. The ultimate goal of any education objective will need to face the employment, to serve the society, and it is especially true for the specialty of fine arts. Especially the specialty of fine arts - design that has strong practicality, with quick updating of professional technology and concept, the traditional closed teaching model must be changed. Increase the students' industrial perceptivity and practice ability by establishing entrepreneurship education courses, strengthening the construction of education practice base, increasing the university-enterprise cooperation, and the integrated operation production, learning and research. On the one hand, integrate knowledge into practice environment and the actual project, go deep into the "enterprise class", and drive teaching with the market demand-oriented practical activity. On the other hand, strengthen the teachers' consciousness of lifelong learning, enabling teachers to grasp the employment trend and dynamic industry of various specialties of fine arts, so as to provide students with the most effective development information. Invite the representatives of cultural units and design enterprises of fine arts and frontline staff into the campus, to participate in drafting the training scheme and the curriculum reform discussion, so as to make students be able to access to the application channel of the knowledge and skills that have been acquired, to truly realize the demands of in-service staff's comprehensive ability by specific positions, and can easily perceive the latest design style and application technology in the professional field.

Second, strengthen the attempt and implementation of "workshop" model. In the field of higher education of fine arts in western countries, the teaching model of "teacher + workshop + case" is applied widely. Part of the student professional course is taught in the teacher's workshop, teachers can teach the knowledge and skills in specific case implementation and creative practice. In some universities in our country, this model is also implemented positively. But because of the large base of students and limited teacher resources, currently, it cannot be implemented fully in the stage of undergraduate course teaching. But teachers can select the advanced ideas and excellent practices as a complement form of inside and outside class teaching. "Workshop" model was originated from the Bauhaus workshop and was generated with the development of heavy industry in Germany [1]. Bauhaus insisted that students shall personally participate in product creation and production, and gave full play to their potential creativity, which has broken through the limitations of previous "empty talk". Bauhaus believes that technology and manual skill can be taught, artistic appreciation is also contained in it. At the same time, he argued that the students shall put design results into practice, creating the new space combining modern design with industrial production. School can organize the students with solid professional skills, strong aggressiveness and complementary advantages to form a creative team. Take the factors such as students' knowledge level, learning ability and teaching target into full consideration, and combine with market demand and industry trend of technology, to select the project tasks with specific theme and contents both inside and outside school, thus to complete the whole project in the form of division of labor under the teachers' participation and guidance and to push forward to practical application. The main body of the "workshop" is the student creative team. In the whole process, the teacher is only responsible for introducing the project, guiding the team members and organizing discussion 
according to project requirement and make evaluation. In creative practices, the harvest of "workshop" members is not only the sense of achievement of transforming learning results into the market value, but also will gain the rapid development of professional ability, cooperation ability and entrepreneurship ability. The pattern of solid state can be broken in order to expand the influence of the "workshop", and adopt the dynamic way of personnel mobility, so as to provide more training opportunities. The lower grade students can also be absorbed into the art class and regular salons belonging to the "workshop", to achieve mentoring within the same specialty and between high and low Grades.

Third, actively encourage the learning behavior of "replacing training with competition". As for various specialties of fine arts, there are various levels and various kinds of creative and design competition each year. Colleges and universities of fine arts can actively create competition environment as well as organize professional skills contest activity and excellent works competition, to cultivate the students' participating consciousness through a series of activities, and sum up experience, build up their confidence and guide senior students participate the competition facing the society and industry fields. Through the entire process, the contestants will gradually discover the competition that can combine their own advantages, and enhance winning probability through contacting the industrial regulations and perfecting techniques. In interview survey, there are a few students, though still studying in school, but have repeatedly won the championship in domestic and foreign well-known design competitions, being the is famous rising star in the industry. This phenomenon tells us that under the wide support by the school and teachers' guidance, learning behavior of "replacing training with competition" is worthy of promotion, and will be a special way of efficient learning for students of fine arts.

\section{REFERENCES}

[1] Mei Baoshu. New Century-oriented Aesthetic Education and Quality Education [M]. Beijing: People's Publishing House, 2004

[2] Zhu Kongjun. Theory and Method of University Student Management [M]. Beijing: People's Publishing House,2010

[3] Li Yu. Analysis of Ideological Characteristics of Students of Fine Arts and Educational Management Strategies [J]. Journal of Hunan School of Administration, 2006(01):45-46.

[4] Zhao Yu. Bauhaus: Idealistic Art Education [J]. World Vision, 2006(08):40-43.

[5] Zou Xingping, Ai Chujun. Analysis of the Characteristics of Graduates of Fine Arts and the Problems [J]. China University Students Career Guide, 2007(16):15-16. 